\title{
AS OCUPAÇÕES URBANAS NA MÍDIA LOCAL: UMA ANÁLISE DAS NOTÍCIAS E DOS COMENTÁRIOS SOBRE AS AÇÕES DOS SEM-TETO EM UBERLÂNDIA - MG
}

Amanda Silva Almeida

Graduanda em Geografia, PET Geografia MEC/UFU - Universidade Federal de Uberlândia amandhaalmeiida@gmail.com

\begin{abstract}
Resumo
O presente trabalho visa compreender o fenômeno das ocupações urbanas em Uberlândia - MG e como a mídia local, em publicações digitais, noticia ações e temas relacionados às ocupações dos sem-teto em Uberlândia, particularmente no que se refere ao Movimento dos Trabalhadores Sem Teto do Brasil (MTST), que ocupa na cidade uma série de terrenos. A pesquisa avalia como a mídia se manifesta sobre a condição e a problemática dos sem-teto e ao movimento que os organiza, bem como a população (através dos comentários das reportagens), compreende e se manifesta sobre o tema.
\end{abstract}

Palavras-chave: Movimentos sociais urbanos; ocupações urbanas; mídia-local.

\section{THE URBAN OCCUPATIONS IN LOCAL MEDIA: AN ANALYSIS OF NEWS AND COMMENTS ON THE ACTIONS OF HOMELESS IN UBERLÂNDIA - MG}

\begin{abstract}
This study aims to understand the phenomenon of urban occupations in Uberlandia - MG and how the local media in digital publications news actions and issues related to the occupations of the homeless in Uberlandia, particularly with regard to the Workers Movement Homeless Brazil (MTST), which occupies a series of lands in the city. The research assesses how the media manifests about the condition of the problematic to the homeless and the movement that organizes them, as well as the population (through the comments of the reports), understands and manifests on the subject.
\end{abstract}

Keywords: Urban social movements; urban occupations; media-local. 


\section{Introdução}

O município de Uberlândia - MG, localizado no Triangulo Mineiro, tem apresentado significativo crescimento populacional e consequente expansão urbana nas últimas décadas. Com uma população estimada em 683.247 habitantes, de acordo com o IBGE (2018), a cidade se destaca como centro regional, principalmente pelas ofertas do setor de serviços, resultando em um PIB municipal que ultrapassa o de diversas capitais brasileiras.

No entanto, apesar do crescimento econômico e de sua expansão urbana, a cidade conhece também um aprofundamento dos problemas urbanos relacionados ao contexto da habitação social. Uberlândia é historicamente marcada por processos de especulação imobiliária (BESSA; SOARES, 1998), o que implica na valorização de bairros, construção de vários condomínios fechados ao longo dos anos e quantidade significativa de imóveis vazios no espaço urbano. Também se nota o aumento gradual de assentamentos e moradias precárias no município devido à ausência de políticas habitacionais verdadeiramente preocupadas com a escassez de moradia, prejudicando principalmente os moradores em condição de vulnerabilidade social e econômica. Essa situação tem promovido o aparecimento de diversos movimentos sociais voltados às estratégias de ocupações urbanas e de luta constante pelo direito à moradia, garantido pela Constituição Federal de 1988.

A partir da problemática da moradia que atinge Uberlândia, é significativo estudar como os veículos de informação apresentam e contextualizam a situação das ocupações dos sem-teto na cidade. A mídia vem obtendo cada vez mais espaço no que se diz a respeito à difusão de informação no século XXI, visto que, com a revolução técnica cientifica informacional (SANTOS, 2000) presente na sociedade atual, a intensificação do uso da internet vem possibilitando diversas interações no âmbito social, cultural e econômico, o que facilita gradativamente as manifestações da mídia na internet e a possibilidade dos veículos de informação obter diversos patrocínios que influenciem na publicação de notícias, criando imagens e estereótipos acerca dos problemas que abatem o país, o que não é diferente no que se refere à questão da habitação e da luta por direitos sociais.

\section{Materiais e métodos}

A pesquisa possui como procedimentos metodológicos centrais, levantamento de referenciais teóricos, a fim de contextualizar o meio urbano no modo de produção vigente, bem como o levantamento de dados na mídia local, como forma de obtenção de informações a respeito das ocupações urbanas de Uberlândia. Reportagens foram levantadas e classificadas, 


\section{Amanda Silva Almeida}

entre 2011 e 2017 (período em que foi possível reconhecer e obter este tipo de dado na mídia local), visando organizar por meio de categorização as reportagens e comentários, bem como elaborar gráficos que subsidiassem a compreensão do fenômeno avaliado.

\section{Resultados e discussão}

\section{O fenômeno das ocupações em Uberlândia - MG}

O espaço urbano em Uberlândia - MG é marcado pelo contexto de perversidade próprio da condição das cidades brasileiras e do modo de produção capitalista vigente. Em decorrência do neoliberalismo, o Estado se ausenta das preocupações sociais, deixa de garantir à nação direitos básicos, como é o caso da moradia, enquanto que o capital imobiliário, hoje inclusive permeado por nexos do capital financeiro, permite com que as cidades e a produção da moradia sejam absolutamente pensadas como um grande "negócio". Nas palavras de Maricato, "Os capitais que ganham com a produção e exploração do espaço urbano agem em função do seu valor de troca. Para eles, a cidade é a mercadoria.” (MARICATO, 2015 p.23)

Mapa 1. Localização de Uberlândia - MG

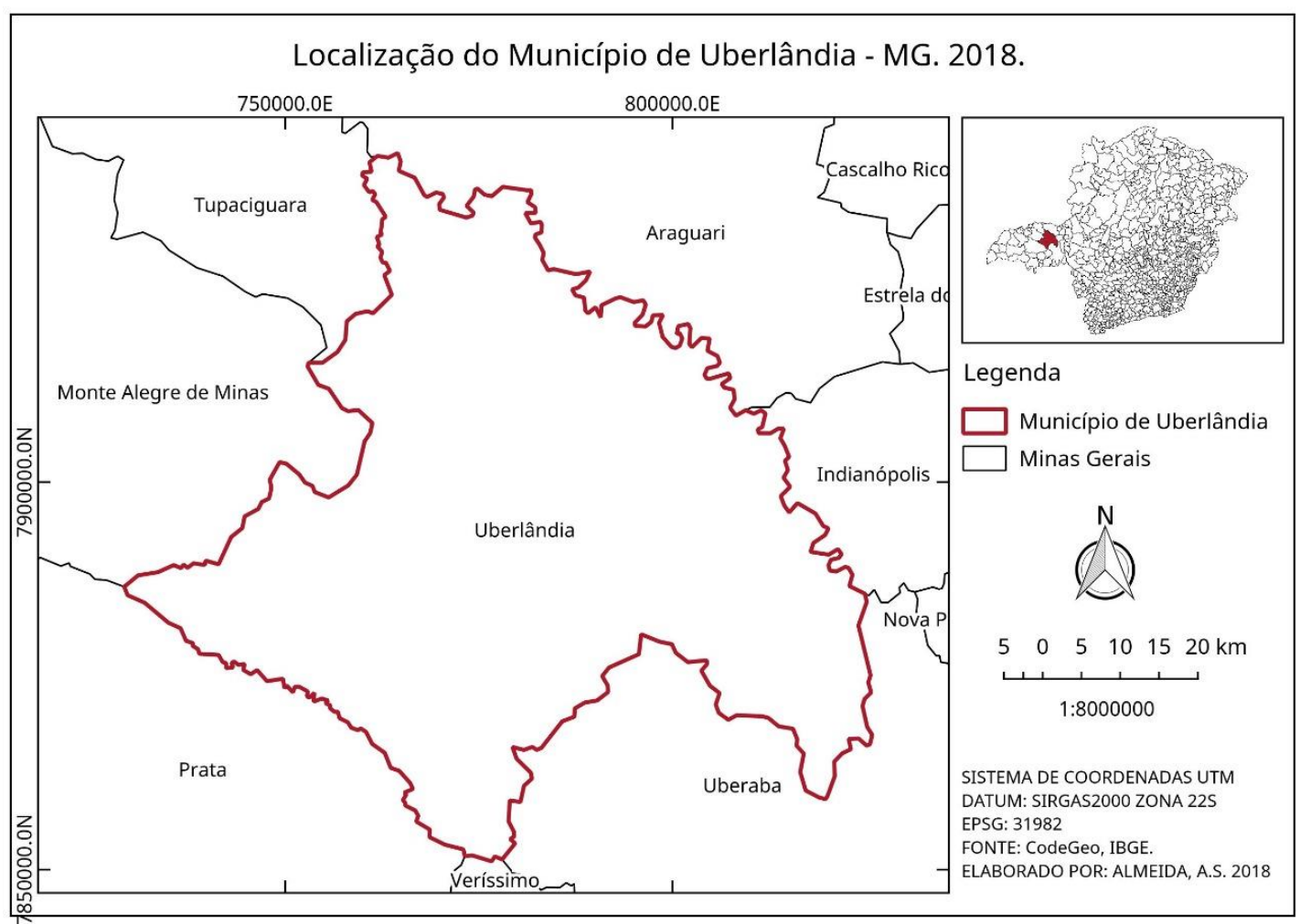

Fonte: ALMEIDA, 2018 
A especulação imobiliária age em função da reprodução ampliada do capital, o que configura e fragmenta o espaço urbano, potencializando a reprodução e a ampliação das desigualdades sociais, uma vez que o Estado, em junção aos interesses do mercado, investe em determinadas áreas, a partir de especificidades como a localização e o maior desenvolvimento da infraestrutura urbana, aumentando dessa maneira o preço dos imóveis de acordo com a valorização do meio construído. Em contrapartida, também relega para segundo plano as áreas periféricas e bairros afastados, que menos correspondem a tal dinâmica de valorização, para onde se destinam as classes pobres, pois o preço das terras, imóveis e alugueis figuram como saídas mais “acessíveis” para a população pobre.

O sentido da intervenção no urbano une o político e o econômico a partir de estratégias que visam permitir a realização do valor que tem o Estado como orientador dos investimentos por meio da construção de infraestrutura e de normas, viabilizando a reprodução do capital. Há, portanto, uma violência inerente a esse processo de produção do espaço urbano sob o capitalismo (CARLOS, 2013 p. 104).

Conforme Carlos (2013), é possível afirmar que os agentes econômicos com a permissão do Estado, modificam a produção do espaço urbano em Uberlândia, de acordo com os interesses do capital imobiliário, bem como também gera um processo que reproduz desigualdades socioespaciais, com a segregação de bairros periféricos, e desta forma de algum modo também contribui com o aumento de ocupações na cidade.

É expressivo a especulação imobiliária estabelecida em Uberlândia, pois são significativos os aumentos constantes no preço da terra em perímetro urbano, para a compra de imóveis, bem como também dos alugueis, dificultando sua aquisição e locação pelas classes mais pobres. Mesmo políticas federais recentes, voltadas para a produção de milhares de moradias de interesse social, como é o caso dos empreendimentos do Minha Casa, Minha Vida (a partir de 2009, com mais de 8 mil moradias destinadas à chamada Faixa 1 em Uberlândia), o déficit habitacional entre os maios pobres (inclusive porque que não conseguem atender a todas as exigências) permanece alto.

Logo, à medida em que crescem empreendimentos privados (inclusive os de luxo), e também o número de imóveis vazios, aumenta o déficit habitacional, bem como as ocupações, que por vezes, se configuram como a única alternativa encontrada pelos trabalhadores de Uberlândia, visto que, mesmo nos bairros periféricos, o preço dos terrenos é alto. 
As ocupações urbanas se manifestam no espaço como forma de resistência à produção da cidade como mercadoria à ineficiência do Estado ao cumprimento de políticas habitacionais, visto que, o Art. $6^{\circ}$ da Constituição Federal, que se diz respeito ao direito à moradia, é sistematicamente negado. Em Uberlândia, especialmente após o ano de 2010, é evidenciado um grande número de ocupações, sobretudo do MTST - Movimento dos Trabalhadores Sem Teto, sendo a Ocupação do Glória, localizada junto a BR-050, uma das maiores do país (mais de 2 mil famílias).

Figura 1. Ocupação Glória, com mais de duas mil famílias em Uberlândia - MG

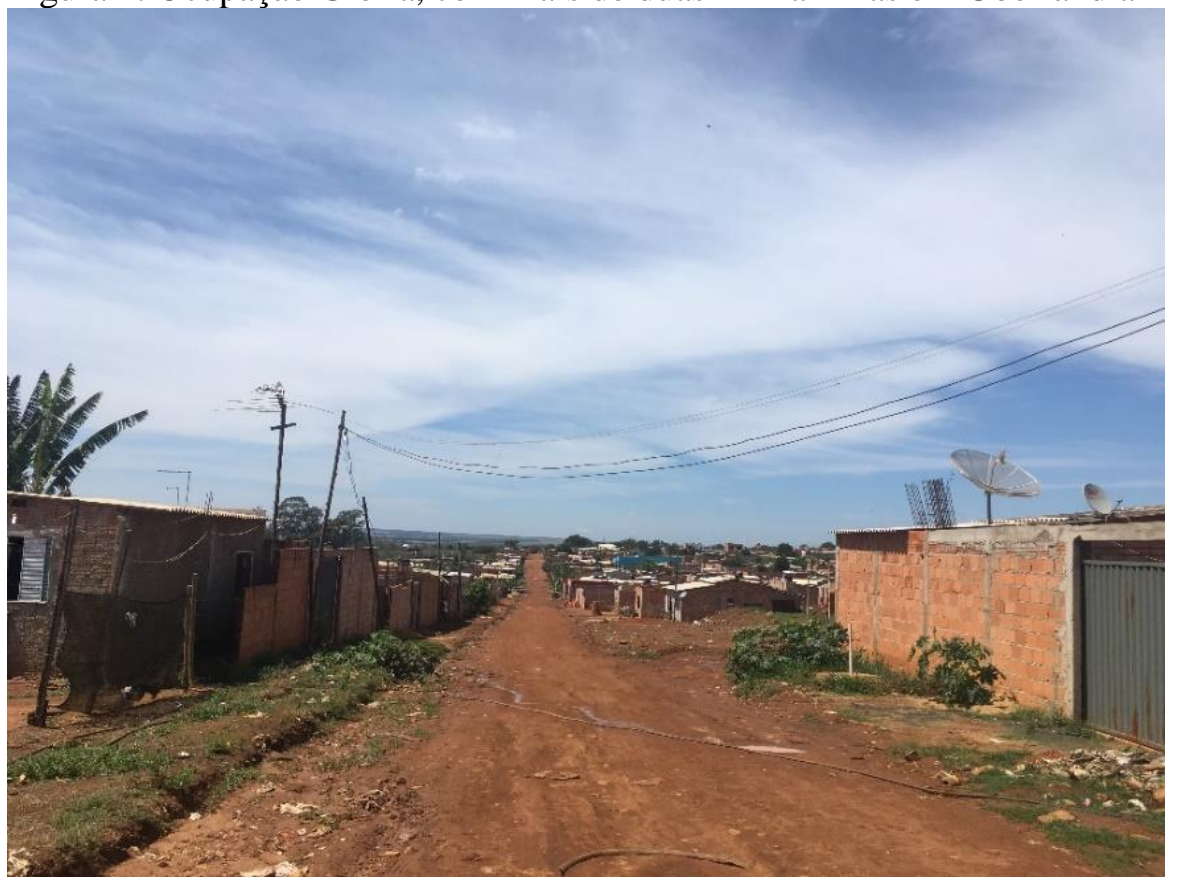

Foto: ALMEIDA, 2018

Os movimentos sociais reivindicam e praticam a luta ao direito à cidade, bem como a permanência do direito à moradia e a ocupação do espaço urbano através de outras estratégias. Para Rodrigues (2007) "Os movimentos sociais "reafirmam o direito universal ao trabalho, educação, saúde, terra para plantar, terra para morar, a igualdade, a universalidade de acesso à moradia, saneamento básico, transportes coletivos, o direito à cidade." Logo, os movimentos sociais, sobretudo ao que se diz respeito ao meio urbano, figuram como manifestação mais direta de oposição à lógica da reprodução ampliada do capital, que orienta o mercado imobiliário na produção da moradia nas cidades. 


\section{A dinâmica de poder da mídia frente ao contexto das ocupações urbanas em Uberlândia - MG: análise das notícias e dos comentários na mídia local}

Segundo Romanet (2013), é perceptível uma nova configuração dos meios de comunicação na Globalização. O neoliberalismo se difunde entre o poder econômico-financeiro e midiático, a fim de concentrar o poder do convencimento na notícia promovida.

Nesse sentido, a globalização e o neoliberalismo potencializam e controlam a produção de notícias, que se adequam conforme os interesses dos agentes que controlam o mercado, bem como evitam qualquer tipo de questionamento. Para Ribeiro (1991) "O sistema moderno de comunicação no Brasil, em sua face política, pode ser compreendido como parte do aparelho institucional criado para o desenvolvimento de estratégias de controle do território nacional e, em sua face econômica, como articulador e agilizador de mercados".

Tabela 1. Analise das reportagens da mídia local

\begin{tabular}{|c|c|}
\hline Mídia-Local & Número de notícias \\
\hline Jornal Correio De Uberlândia & 65 \\
\hline TV Integração (G1: Triângulo Mineiro) & 15 \\
\hline TV Vitoriosa (SBT: UIPI) & 6 \\
\hline Total de notícias analisadas & 86 \\
\hline
\end{tabular}

Fonte: Elaboração própria, a partir de jornais locais.

Através de levantamentos na mídia (em publicações digitais de jornais locais), foi identificado entre o período de 24/10/2011 até 04/04/2017, 86 reportagens sobre as ocupações dos sem teto em Uberlândia. Também a partir do mesmo levantamento, obtivemos o anúncio da ocorrência de 24 ocupações, ocorridas entre os anos de 2011 e 2017 (Gráfico 1), ainda que algumas tenham sido de modo rápido objeto de reintegração de posse.

Realizando uma análise dos conteúdos, as reportagens se preocupam, predominantemente, em informar novas ocupações, relatar reintegrações de posse e negociações, além de retratarem com frequência as manifestações realizadas pelos sem teto, além de outras temáticas incluídas na categorização das reportagens, conforme apresentamos a seguir (Gráfico 2). 
Gráfico 1. Ocupações de sem teto divulgadas na mídia local de Uberlândia-MG

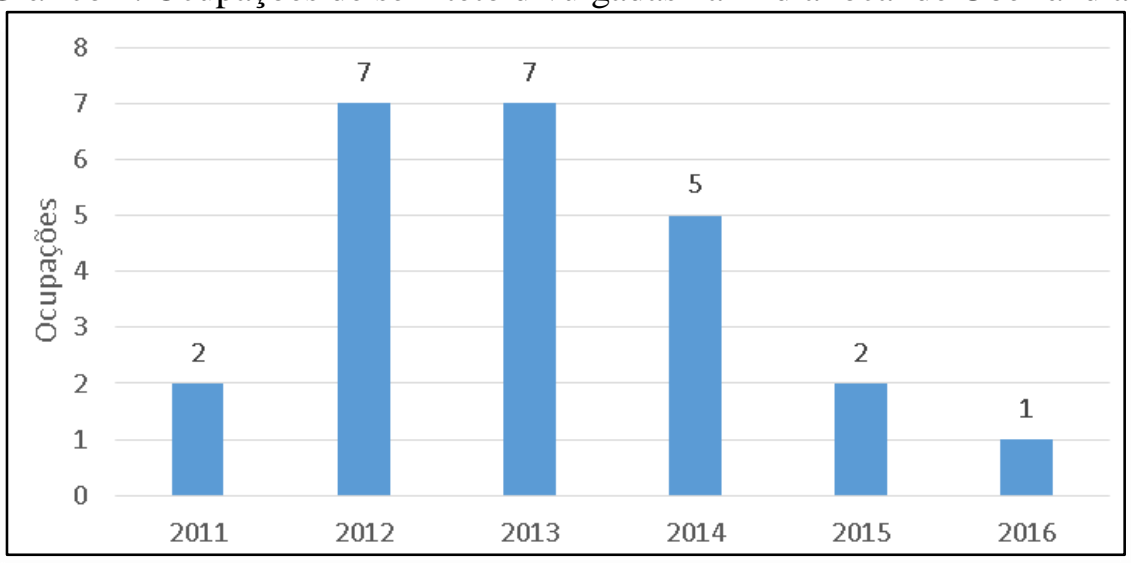

Fonte: Elaboração própria, a partir de jornais locais.

Gráfico 2. Temas das Reportagens Relacionadas às Ocupações Urbanas de Uberlândia - MG, em publicações digitais de jornais locais.

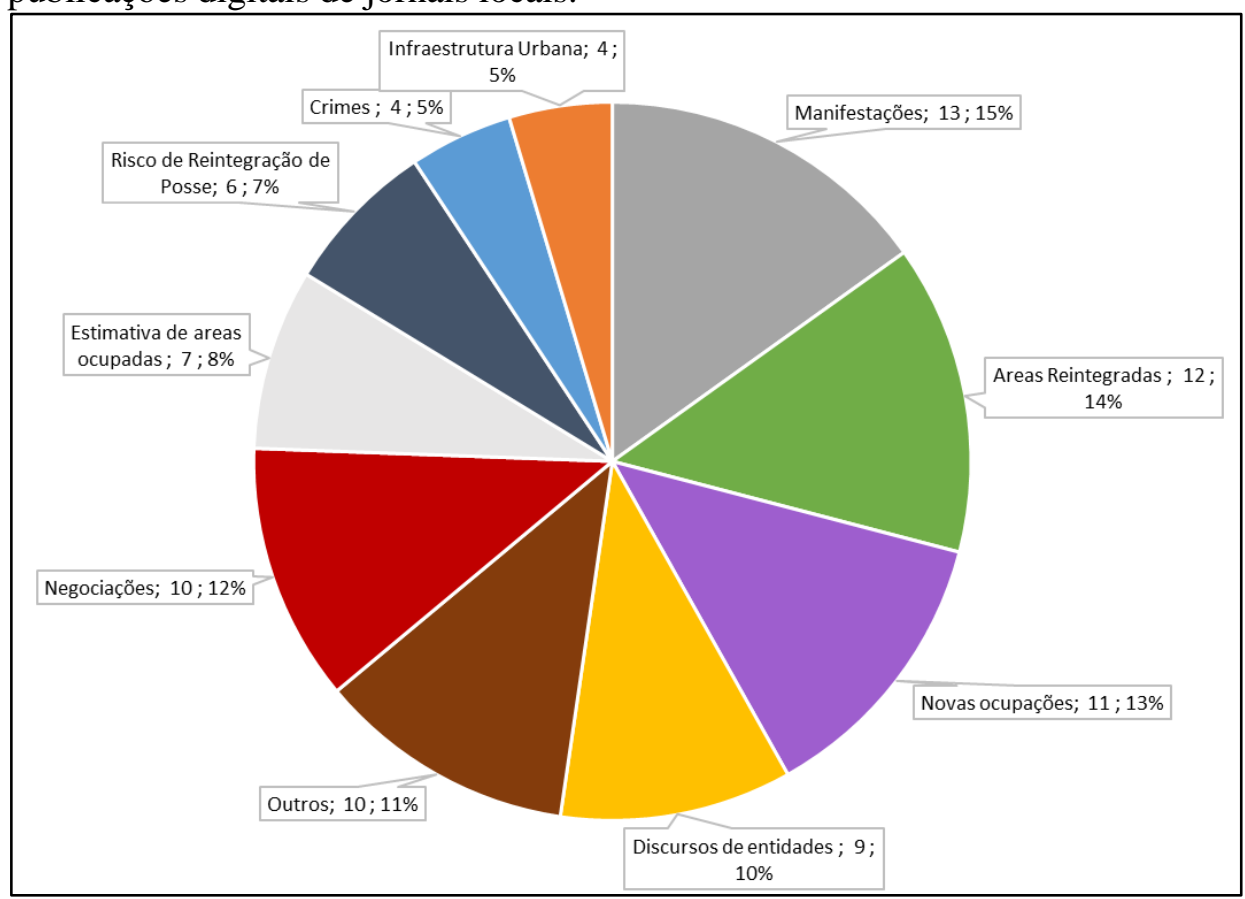

Número de reportagens publicadas / Porcentagem (\%) frente ao total de publicações. Fonte: Elaboração própria, a partir de levantamentos na mídia digital (jornais locais)

Avaliando o conjunto das reportagens, encontramos os seguintes assuntos, por nós categorizados: "Manifestações", protestos e ocupações do movimento sem-teto em Uberlândia (15\% do total de reportagens levantadas); “Áreas Reintegradas”, divulgando ocupações que foram alvo de reintegração de posse (14\% do total levantado); "Novas Ocupações", registros de novas ocupações dos sem-teto em Uberlândia (13\%); "Discursos de entidades": Pronunciamentos de entidades como o prefeitura, Policia Militar, advogados, Universidade 
Amanda Silva Almeida

Federal de Uberlândia, etc. no que se diz respeito as ocupações urbanas (10\%); "Negociações", relatando negociações entre o movimento do sem-teto e o Estado a fim de regularizar ou realizar a reintegração de posse nas áreas ocupadas pelo sem-teto de Uberlândia; "Estimativa de Áreas Ocupadas", levantamentos de dados sobre as áreas ocupadas, podendo incluir também estimativa de ocupantes e número famílias nas ocupações do sem-teto (8\%); "Risco de Reintegração de Posse", anúncio de ações judiciais, avisos de reintegração de posse nas ocupações (7\%); "Crimes”, nesta categoria, relatos de crimes ocorridos nas ocupações (em geral ressaltando a ideia de violência inerente a esses espaços) (5\%); "Infraestrutura Urbana", apontando problemas relacionados à falta de infraestrutura urbana nas ocupações, tais como danos ambientais e ausência de rede elétrica (5\%), e, por fim, “Outros temas”, onde agrupamos artigos de opinião, medidas provisórias e doações de terras e outros assuntos relacionados às ocupações $(11 \%)$.

A mídia aponta diversas dificuldades ao reconhecer as ocupações como legítimas, sendo utilizado na maioria das notícias o termo "invasão", ao invés de "ocupação", indicando portanto postura de criminalização dos ocupantes e tratando o problema da moradia como um problema individual das famílias (não se atinge em geral a compreensão da problemática que historicamente acomete o país no que se diz respeito ao meio urbano). Tal situação pode talvez ser compreendida devido ao próprio interesse dos meios de comunicação, visto que, segundo Erminia Maricato (2015, p19) "A mídia do mainstream trata de cidades o tempo todo, entretanto, raramente a toma como produto ou mercadoria que intermedia os conflitos entre classes sociais. Afinal, o capital imobiliário é um grande anunciante, patrocinador da grande mídia". Vale salientar que, das mais de 80 reportagens encontradas sobre as ocupações urbanas em Uberlândia, em nenhuma delas houve preocupação jornalística que apontasse para o tema da especulação imobiliária e demais problemas urbanos que atingem a população pobre de Uberlândia.

A própria mídia produz confusões ao utilizar em uma mesma reportagem os conceitos de "invasão" e "ocupação" (Figura 2). A mesma reportagem, do jornal "Correio de Uberlândia", aponta o número de famílias em ocupações, totalizando mais de 5 mil famílias em ocupações dos sem teto. No entanto, não fora realizada discussão à altura do problema habitacional de Uberlândia em nenhum momento. 
Figura 2. Síntese da situação das "invasões" (como usualmente denominadas nos jornais), em um dos principais veículos da mídia local.

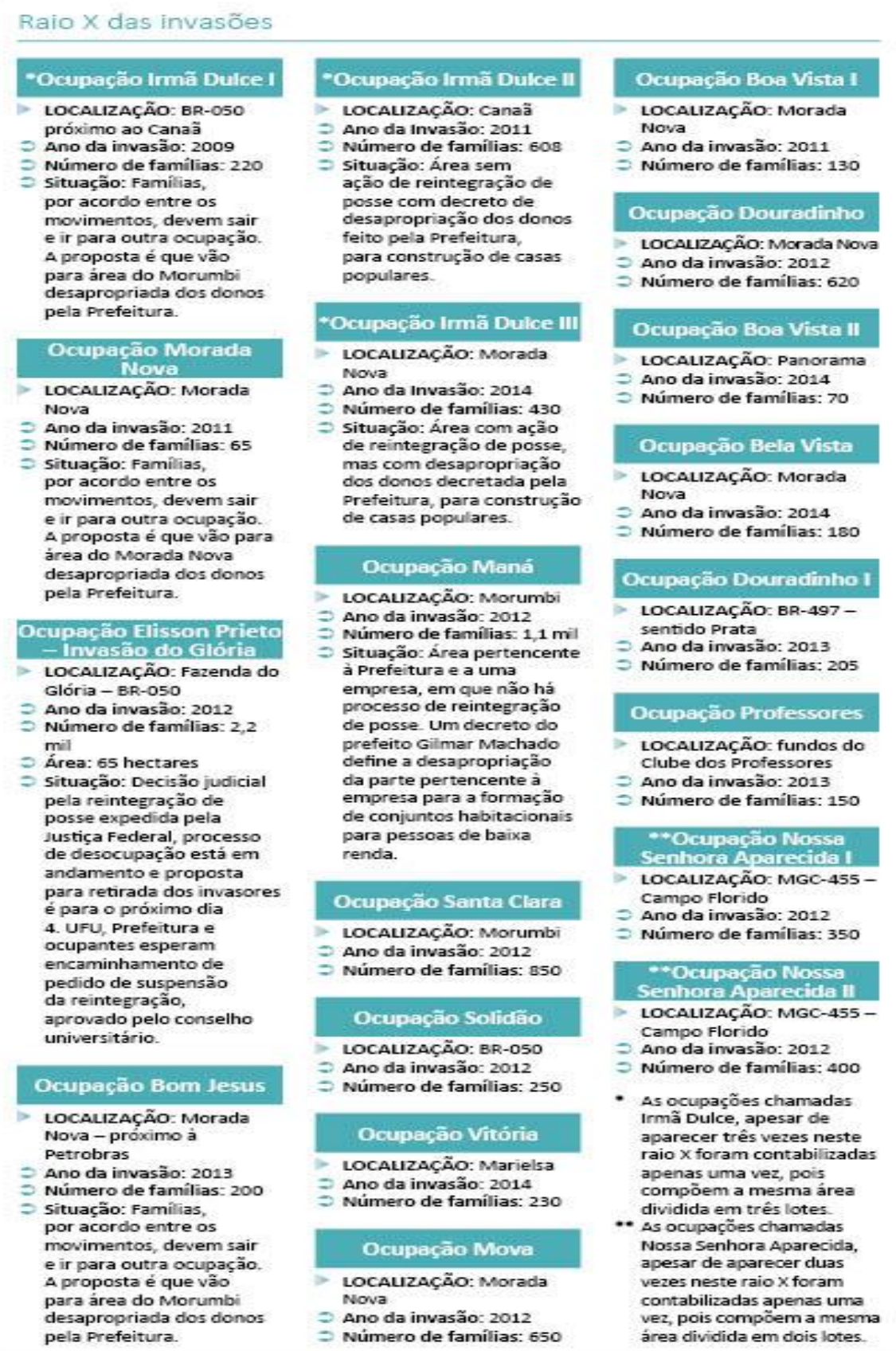

Fonte: Jornal Correio. Disponível em: <http://www.correiodeuberlandia.com.br/cidade-e-regiao/pmfez-35-reintegracoes-de-posse-em-2014-em-uberlandia/>. Acesso em: 05 out. 2017.

No que se diz respeito aos comentários elaborados pelos leitores dos jornais, é visível o predomínio de manifestações que em geral criticam e mesmo criminalizam as ocupações, os moradores e movimentos sociais, em geral apontando falta de compreensão dos problemas sociais, ou seja, não reconhecendo o direito à habitação como direito constitucional. Não são 
poucos os comentários que caracterizam os ocupantes como "oportunistas", "vagabundos", entre outros termos pejorativos (Figura 3).

Figura 3. Alguns comentários de leitores sobre notícia retratando ligações irregulares de água e energia em ocupações no Jornal Correio de Uberlândia

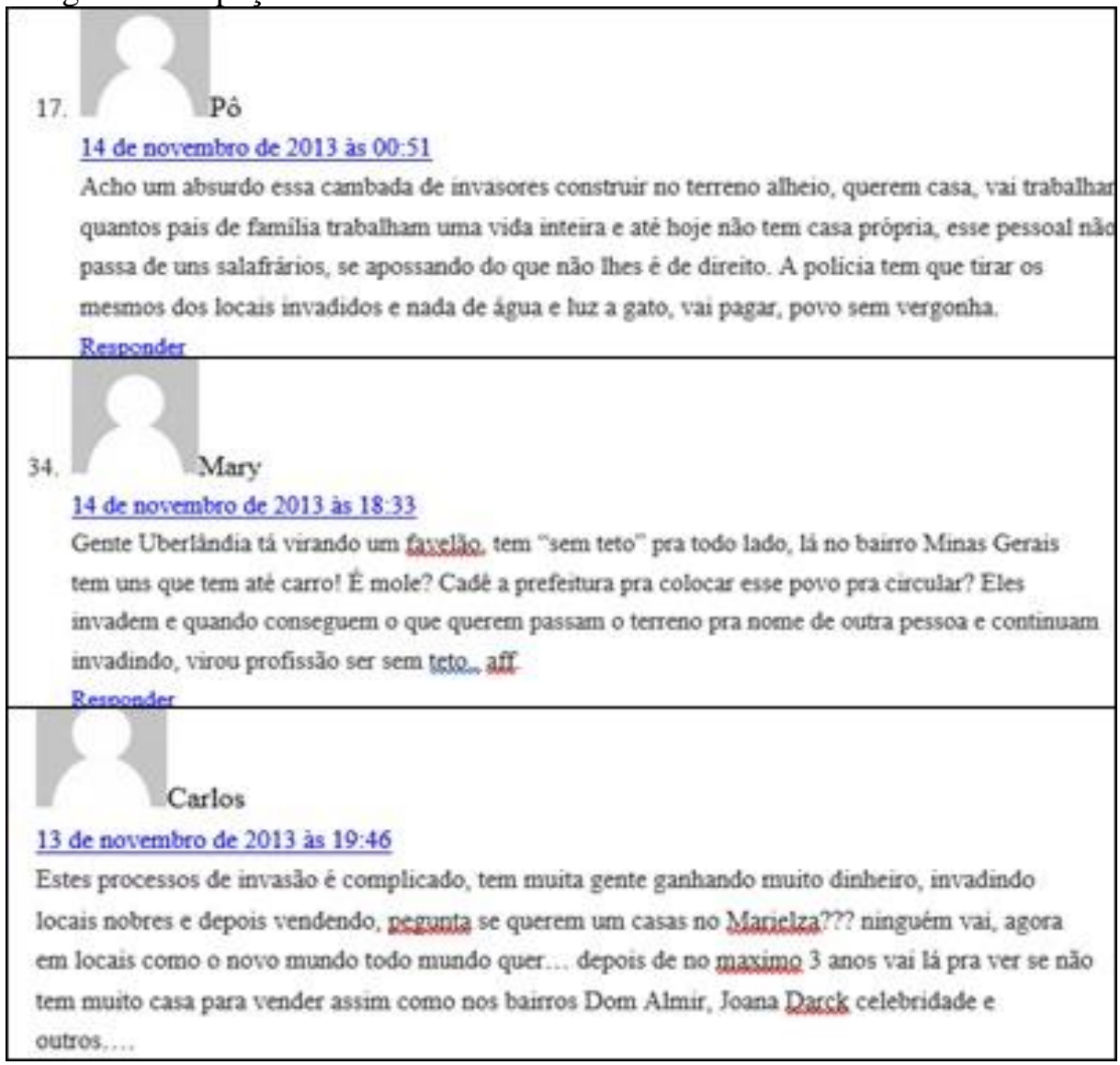

Fonte: Jornal Correio de Uberlândia (05/10/2017)

Os comentários também apresentam discursos de ódio em relação as ocupações e seus ocupantes, colocam a frente a condição do direito à propriedade privada e não fazem alusão ao direito à moradia e à função social da terra/propriedade estabelecida na Constituição Federal.

\section{Considerações finais}

As diversas ocupações inseridas no espaço urbano de Uberlândia, que se intensificaram sobretudo entre os anos 2011-2016, se lidos à luz da Constituição Federal, que garante o direito à moradia (Art. $6^{\circ}$ da Constituição Federal), poderiam, para além de preconceitos e de discursos de repressão, serem compreendidas como ações de revolta e de manifestação pela exigência de direitos que historicamente tem sido negados à população mais pobre. 
Amanda Silva Almeida

Através de levantamentos na mídia, (em publicações digitais) foi possível identificar 86 reportagens no período de 24/10/2011 até 04/04/2017, retratando a questão das ocupações. As reportagens se preocupam, predominantemente, em informar novas ocupações, relatar reintegrações de posse e negociações, além de retratarem manifestações realizadas pelos sem teto e outras temáticas incluídas na categorização das reportagens. Cabe ressaltar que não houve nenhuma matéria jornalística vinculada à especulação imobiliária e os problemas urbanos que atingem a periferia de Uberlândia. Por sua vez, a mídia desconhece dos problemas da cidade ou no entanto, prefere não os apontar nas reportagens.

Os comentários analisados, em sua grande maioria, representam opiniões pessoais e contrárias às ocupações, marcados pela desqualificação de moradores e pela utilização de adjetivos pejorativos a respeito das famílias e dos movimentos sociais dos sem-teto em Uberlândia - MG. Tal como sugere o conteúdo das reportagens, os comentários quase sempre ignoram a moradia como direito fundamental à dignidade dos cidadãos, a partir de argumentos que acionam o mérito pessoal e o esforço individual como elementos que deveriam presidir o acesso a casa/habitação (essencialmente como mercadoria).

\section{Referências}

BESSA, K. C. F. O; SOARES, B. R. Assentamentos urbanos em Uberlândia: o significado de um novo espaço. História e Perspectivas. Uberlândia, n.18/19, p. 93-130, 1998.

CARLOS, Ana Fani et al. A produção do espaço urbano. São Paulo: Contexto, 2013.

CARLOS, A.F.A.; Alves, G.A.; Padua, R.F. Justiça espacial e o direito à cidade. São Paulo: Contexto, 2017.

CORREIO DE UBERLÂNDIA. Jornal Correio de Uberlândia. Disponível em: <www.correiodeuberlandia.com.br>. Acesso em: 2017-2018

G1. TV Integração. Disponível em: <https://g1.globo.com/mg/triangulo-mineiro/>. Acesso em: 2017-2018

IBGE. População estimada Uberlândia. 2018. Disponível em: <https://cidades.ibge.gov.br/brasil/mg/uberlandia/panorama>. Acesso em: 20 ago. 2018.

MARICATO, E. Para Entender a Crise Urbana. São Paulo: Expressão Popular, 2015

MORAES, Dênis De (Org.). Mídia, Poder e Contrapoder: Da concentração monopólica à democratização da informação. São Paulo: Boitempo; Rio de Janeiro: Faperj, 2013.

RIBEIRO, Ana Clara Torres. Matéria e espírito: o poder (des)organizador dos meios de comunicação. In: PIQUET, Rosélia; RIBEIRO, Ana Clara Torres (Orgs.). Brasil, território da desigualdade: descaminhos da modernização, 1991. p. 44-55. 
Amanda Silva Almeida

RODRIGUES, Arlete Moysés. DESIGUALDADES SOCIOESPACIAIS - A LUTA PELO DIREITO À CIDADE. $2007 . \quad$ Disponível em: <http://revista.fct.unesp.br/index.php/revistacidades/article/viewFile/571/602>. Acesso em: 07 jul. 2018.

SANTOS, M. Por uma outra globalização: do pensamento único à consciência universal. Rio de Janeiro: Record, 2000.

UIPI. TV Vitoriosa. Disponível em: <http://uipi.com.br>. Acesso em: 2017-2018 